University of Nebraska - Lincoln

DigitalCommons@University of Nebraska - Lincoln

Configuration Methodology for Traffic-Responsive Plan Selection: A Global Perspective

\author{
Montasir M. Abbas \\ Virginia Polytechnic Institute and State University \\ Nadeem A. Chaudhary \\ Texas A \& M University - College Station \\ Geza Pesti \\ Texas A \& M University - College Station \\ Anuj Sharma \\ University of Nebraska - Lincoln, anujs@iastate.edu
}

Follow this and additional works at: https://digitalcommons.unl.edu/civilengfacpub

Part of the Civil Engineering Commons

Abbas, Montasir M.; Chaudhary, Nadeem A.; Pesti, Geza; and Sharma, Anuj, "Configuration Methodology for Traffic-Responsive Plan Selection: A Global Perspective" (2005). Civil Engineering Faculty Publications. 18.

https://digitalcommons.unl.edu/civilengfacpub/18

This Article is brought to you for free and open access by the Civil Engineering at DigitalCommons@University of Nebraska - Lincoln. It has been accepted for inclusion in Civil Engineering Faculty Publications by an authorized administrator of DigitalCommons@University of Nebraska - Lincoln. 
Published in Transportation Research Record: Journal of the Transportation Research Board of the National Academies, no. 1925 (2005): 195-204. Copyright 2005 by the National Academies/National Research Council. Used by permission.

\title{
Configuration Methodology for Traffic-Responsive Plan Selection: A Global Perspective
}

\author{
Montasir M. Abbas ${ }^{1}$, Nadeem A. Chaudhary ${ }^{2}$, Geza Pesti ${ }^{2}$ and Anuj Sharma ${ }^{3}$ \\ ${ }^{1}$ Department of Civil and Environmental Engineering, Virginia Polytechnic Institute and State University, Blacksburg, VA \\ ${ }^{2}$ Texas Transportation Institute, Texas A\&M University System, College Station, TX \\ ${ }^{3}$ Department of Civil Engineering, University of Nebraska, Lincoln, NE; asharma3@unl.edu
}

Although several studies have shown the potential great benefits of traffic-responsive plan selection (TRPS) control, timeof-day operation continues to be the primary method used to select patterns for signal control applications. This practice could be largely attributed to the minimal guidelines available on the setup of the TRPS mode. An innovative framework for TRPS system setup is provided, and guidelines for implementing TRPS in a simplified manner are shown. The guidelines, developed at Texas Transportation Institute (TTI), use a comprehensive approach that incorporates a multiobjective evolutionary algorithm and a supervised discriminant analysis. Engineers can directly implement the guidelines presented as an initial design. Hardware-in-the-loop simulation is used to illustrate the performance of TTI's TRPS configuration methodology.

Traffic-responsive plan selection (TRPS) is probably one of the most underutilized features of modem traffic signal controllers. Although several studies have shown the potential great benefits of TRPS control $(1,2)$, time-of-day (TOD) operation continues to be the primary method used to select patterns for signal control applications. This practice could be largely attributed to the minimal guidelines available on the setup of the TRPS mode. In addition, TRPS setup is conceived of as a huge task that requires a considerable amount of time and resources to design, evaluate, and monitor successfully.

The TRPS mode uses count and occupancy data collected from system detectors. The information is aggregated by means of certain master controller functions by using smoothing, scaling, and weighting factors (3-5). These TRPS factors are used to calculate the TRPS parameters to select the most appropriate timing plan. Each system detector is assigned a weighting factor by which its data are multiplied during the aggregation process. In spite of the term's implication, a weighting factor does not emphasize the importance of an individual system detector, as will be discussed later.

The National Transportation Communications for ITS Protocol (NTCIP) 1,210 field management stations draft defines two methods for TRPS operation: pattern-matching algorithms and threshold comparison (6). The pattern-matching algorithms select patterns based on the sum of the deviations of individual count and occupancy values from those stored in the master for each pattern. The threshold method, however, selects alternative timing plans when functions of count and occupancy exceed their thresholds. Although both methods can produce similar results, the threshold method is the one widely implemented by vendors of traffic signal controllers.

The TRPS threshold method utilizes several computa- tional channel (CC) and pattern selection (PS) parameters to arrive at the final selected timing plan. Figure 1 shows a general TRPS mechanism in which occupancy and count information from a group of $n$ system detectors ( $n$ differs from one manufacturer to another) are aggregated into a CC parameter (i.e., by multiplying each system detector by its corresponding weight $W$ ). It should be noted that system detectors used with a CC parameter mayor may not be the same system detectors used with another CC parameter. The name and number of CC parameters in a TRPS system differ from one manufacturer to another. Most TRPS manufacturers, however, agree on the names and number of PS parameters, namely, cycle, split, and offset. Each PS parameter is calculated as a function of several CC parameters. Some of these functions are user selected, and others are predefined by the controller manufacturer.

The master controller compares each PS parameter value with its corresponding threshold to identify the appropriate PS level. The three PS levels are used as index values in a table lookup procedure. The lookup-table entries determine which one of the prestored timing plans will be selected. This cycle-split-offset PS parameter nomenclature can be somewhat confusing to the user. Each PS parameter value merely specifies an index to the TRPS lookup table and not the actual cycle, split, and offset values.

As can be deduced from the foregoing discussion, setting up a TRPS system to work optimally is not a trivial task. The engineer is faced with the challenge of selecting a limited collection of timing plans (16 to 48, depending on the controller type) to provide optimal performance for a wide range of traffic states. In addition, TRPS parameters have to be selected in conjunction with the timing plans to provide a robust and steady operation. When the system is not in a steady state, benefits of a better timing plan might be offset by the delays associated with transitioning between timing plans. Previous research showed that only marginal benefits could be achieved over TOD mode when fluctuation in traffic demand caused frequent timing plan changes (7).

The objectives of this research were to develop a methodology to (a) select a small set of timing plans (within the limitation of the controller) to provide optimal performance of TRPS, and (b) determine the detector weights, threshold, and timing plan lookup tables to provide a steady operation with maximum classification accuracy. Since the methodology developed was anticipated to be complicated, it was also desired to provide a general design that could provide relatively good performance. 


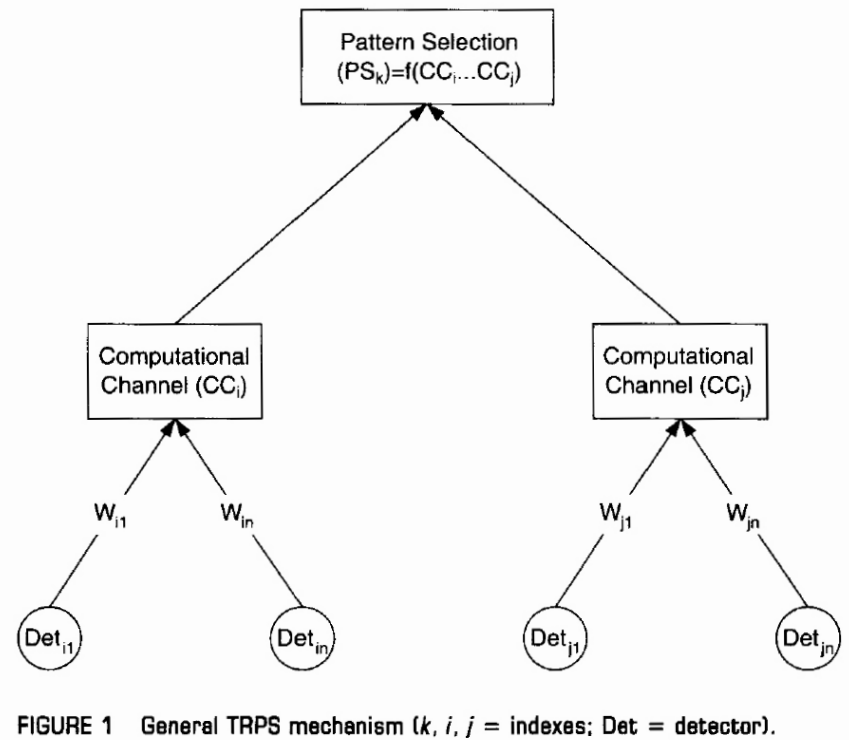

\section{PROPOSED GLOBAL FRAMEWORKFOR TRPS CONFIGURATION}

Recently, the Texas Transportation Institute (TTI) has been developing simplified guidelines for configuration of TRPS systems. The word "simplified" merely refers to the procedure of the field setup itself and not to the development of the guidelines or the research methodology. The goal of TTI's guidelines is to simplify TRPS system setup to the extent of inputting values from tables and charts into the traffic controller to obtain a working system that responds quickly and accurately to changes in traffic conditions or states. This philosophy imposed the great challenge of how to design timing plans and TRPS parameters that would work optimally for a wide range of traffic states. Since the guidelines are designed to handle a general system, a better configuration could exist to handle a specific system in question. The TTI goal, however, is to design these guidelines to provide an initial "one-size-fits-all" easily configured blanket of TRPS systems with good performance. As traffic engineers become more familiar with the TRPS configuration and realize its benefits, further improvement and development of guidelines for more specific cases could be undertaken.

The TTI configuration methodology is introduced here, and TRPS operation by using hardware-in-the-loop (HITL) simulation and the selection of the 1,479 different traffic states used in the analysis are described. The initial pool of 10,353 timing plans was developed by using the PASSER V (8) signal optimization package. A multiobjective evolutionary algorithm was used to select only 14 timing plans from the initial 10,353 timing plans to address all traffic states minimizing overall system delay and stops. The evolutionary algorithm also ensured that traffic states, in their association with the final timing plans, are clustered on the basis of volume. The latter requirement was to simplify the TRPS threshold setup process by having adjacent states assigned to the same timing plans. A supervised discriminant analysis algorithm was developed to calculate the classification accuracy within the structure of TRPS plan assignment. Finally, the multiobjective evolutionary algorithm was used again, integrated with the discriminant analysis algorithm, to determine the final weights assigned to system detectors as well as the thresholds required to switch from one timing plan to another when the traffic state changes into one of their associated conditions.

An example of TRPS performance using HITL simulation is then show cased. The tables provided in this paper are to be used as an initial design. Engineers can fine-tune the thresholds presented here to better suit the traffic distributions in their system. Ultimately, the authors recommend the development of computer software to automate the procedure presented in this paper so that more-customized designs can be produced.

\section{Traffic State Generalization}

To cover all reasonable traffic states in this analysis, a global perspective was used to look at all possible traffic states as shown in Figure 2. The global perspective classifies arterial volume into three main movements: major external movements to the arterial, internal local movements, and additional cross-street movements. Preliminary PASSER runs were conducted to find the realistic limits of each movement in a four-intersection system so that the intersections are not oversaturated. The levels for each external movement are shown in Table 1.

For each level of theinternal local traffic, theinternal turning movements werecalculated on the basis of an assumption that every node produces an equal amount of trips and these trips are equally attracted by other nodes in the network. Levels and resulting interior turning volumes are shown in Table 2.

\section{Traffic State Probability}

To design an optimal selection of timing plans, there is a need to know the probability of occurrence of each traffic state. A traffic state that occurs more frequently should obviously be favored by the algorithm when the timing plans are selected. The probability of a particular state was determined on the basis of the average occurrence of that state as observed in data from three sites in Texas. The probabil- 


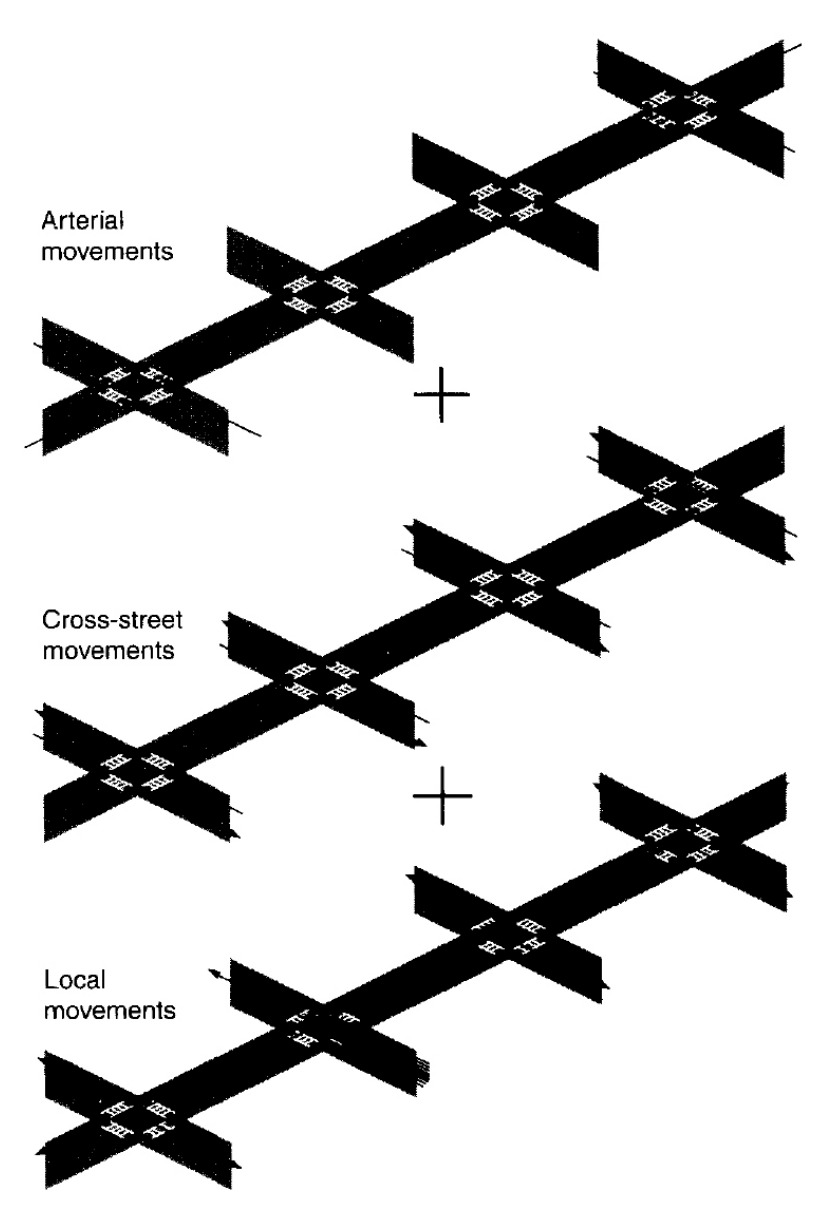

FIGURE 2 Generalized arterial volume distribution.

ity of a state was determined in two steps: (a) determine the probability of occurrence of traffic volume in a major arterial direction and (b) given the major arterial direction, determine the probability of all other volumes in the other direction. Figure 3 shows the concept of major-and minor-axis state probabilities in an arterial system. The final state probability was determined as the product of two probabilities.

From the data collected in the Odem, Lampasas, and Brownwood closed-loop systems in Texas, distribution fits were conducted to obtain a general state probability distribution. Figure 4 shows the major probability dis-tribution fitted to field data.

The major volume distribution was found to follow a gen- eral Gaussian model of the following form with an $R$ square of 0.85 :

$$
Y=a e^{-\left[\frac{(x-b)}{c}\right]^{2}}
$$

where

$$
\begin{aligned}
& Y=\text { probability of occurrence, } \\
& x=\text { traffic volume, } \\
& a=0.01464 \\
& b=164.8, \text { and } \\
& c=615.5
\end{aligned}
$$

For the minor probability, normal distributions were fitted. The mean was the input as the major level. The best fit for each minor axis resulted in the determination of the standard deviation for various minor-axis volumes. The standard deviations are shown in Table 3.

\section{Timing Plan Generation}

The proposed global perspective resulted in the formation of 3,888 traffic states: ( $4 \times 3 \times 3)$ eastbound external movements times $(4 \times 3 \times 3)$ westbound external movements times 3 cross-street levels. PASSER V was used to obtain timing plans for each of the states with seven cycles each (cycle lengths of 60, 75, 90, 100, 120, 150, and 180 seconds). Next, all oversaturated states were removed, leaving only 1,479 states. PASSER V was then run again to evaluate the performance of each of these timing plans with each of the original states, and a matrix of delay and number of stops was obtained for each of the combinations to be used as an input for the genetic algorithm (GA) optimization.

After the state probabilities and state-plan delay mapping were obtained, a multiobjective GA was used to determine a maximum of 16 timing plans (a limitation imposed by traffic controllers) that would result in minimal delay, stops, and degree of detachment (DOD) among the traffic states. The DOD measures the degree by which a traffic state is detached from adjacent states. In this context, detachment occurs when the adjacent state (one that has one level below or one above the current state's level) is associated with a different timing plan. If timing plan assignments are scattered as small clusters throughout the state space, a high DOD value is obtained, whereas solutions in which the timing plan assignments form big clusters in the state space have low DOD values. The multiobjective GA resulted in a selection of only 14 timing plans to handle all traffic states, with a reduction of $53 \%$

TABLE 1 Volume Levels in Vehicles per Hour for Arterial External Movements

\begin{tabular}{lccccrr}
\hline \multicolumn{7}{l}{ External Movement } \\
\cline { 2 - 6 } Level & EB-Through & SB-Left & NB-Right & WB-Through & NB-Left & SB-Right \\
\hline 1 & 400 & 0 & 0 & 400 & 0 & 0 \\
2 & 800 & 200 & 200 & 800 & 200 & 200 \\
3 & 1200 & 300 & 300 & 1200 & 300 & 300 \\
4 & 1600 & - & - & 1600 & - & - \\
\hline
\end{tabular}

EB = eastbound; $\mathrm{SB}=$ southbound $\mathrm{NB}=$ northbound; $\mathrm{WB}=$ westbound. 
TABLE 2 Volume Levels in Vehicles per Hour for Internal Local Movements

\begin{tabular}{|c|c|c|c|c|c|c|c|c|c|c|c|c|c|c|}
\hline \multirow{3}{*}{$\begin{array}{l}\text { Cross } \\
\text { Street } \\
\text { Level }\end{array}$} & \multirow[b]{3}{*}{ Volume } & \multirow[b]{3}{*}{ Intersection } & \multicolumn{12}{|c|}{ Direction } \\
\hline & & & \multicolumn{3}{|l|}{ EB } & \multicolumn{3}{|l|}{ WB } & \multicolumn{3}{|l|}{ NB } & \multicolumn{3}{|l|}{ SB } \\
\hline & & & $\mathrm{L}$ & $\mathrm{T}$ & $\mathrm{R}$ & $\mathrm{L}$ & $\mathrm{T}$ & $\mathrm{R}$ & $\mathrm{L}$ & $\mathrm{T}$ & $\mathrm{R}$ & $\mathrm{L}$ & $T$ & $\mathrm{R}$ \\
\hline \multirow[t]{4}{*}{1} & 150 & 1 & 21 & 127 & 21 & 134 & 113 & 134 & 131 & 19 & 19 & 19 & 19 & 131 \\
\hline & & 2 & 59 & 272 & 59 & 96 & 267 & 96 & 94 & 19 & 56 & 56 & 19 & 94 \\
\hline & & 3 & 96 & 267 & 96 & 59 & 272 & 59 & 56 & 19 & 94 & 94 & 19 & 56 \\
\hline & & 4 & 134 & 113 & 134 & 21 & 127 & 21 & 19 & 19 & 131 & 131 & 19 & 19 \\
\hline \multirow[t]{4}{*}{2} & 300 & 1 & 42 & 253 & 42 & 267 & $2 z 5$ & 267 & 263 & 38 & 38 & 38 & 38 & 263 \\
\hline & & 2 & 117 & 544 & 117 & 192 & 534 & 192 & 188 & 38 & 113 & 113 & 38 & 188 \\
\hline & & 3 & 192 & 534 & 192 & 117 & 544 & 117 & 113 & 38 & 188 & 188 & 38 & 113 \\
\hline & & 4 & 267 & 225 & 267 & 42 & 253 & 42 & 38 & 38 & 263 & 263 & 38 & 38 \\
\hline \multirow[t]{4}{*}{3} & $300+100$ & 1 & 42 & 253 & 42 & 267 & 225 & 267 & 263 & 138 & 38 & 38 & 138 & 263 \\
\hline & & 2 & 117 & 544 & 117 & 192 & 534 & 192 & 188 & 138 & 113 & 113 & 138 & 188 \\
\hline & & 3 & 192 & 534 & 192 & 117 & 544 & 117 & 113 & 138 & 188 & 188 & 138 & 113 \\
\hline & & 4 & 267 & 225 & 267 & 42 & 253 & 42 & 38 & 138 & 263 & 263 & 138 & 38 \\
\hline
\end{tabular}

in delay and $16 \%$ in stops in comparison with the worst solution encountered during the optimization run. This result could be interpreted as $53 \%$ savings in delay and $16 \%$ savings in stops compared with an old TOD design with 14 timing plans (which is rare). The benefits compared with the typical three-plan old TOD design would be even higher (a typical three-plan TOD design is less optimal than a 14-plan TOD design since a wider range of traffic will need to be addressed by the same timing plan).

\section{Supervised Discriminant Analysis}

A primary task in TRPS is to define a set of state variable

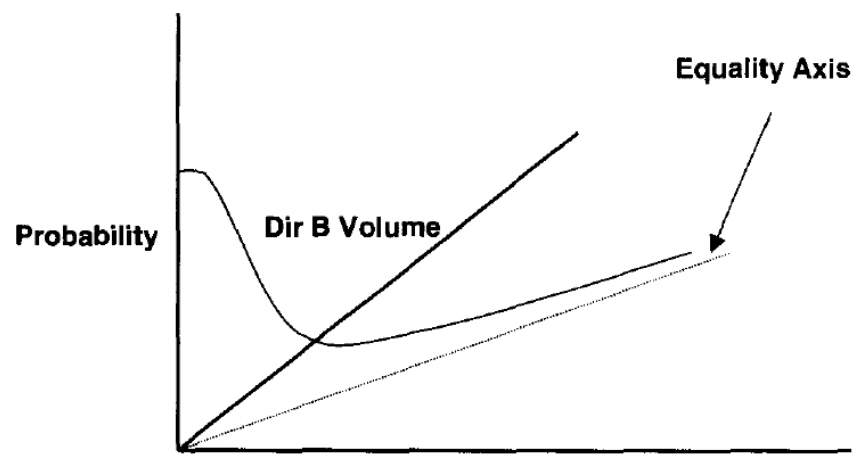

Dir A Volume

(a)

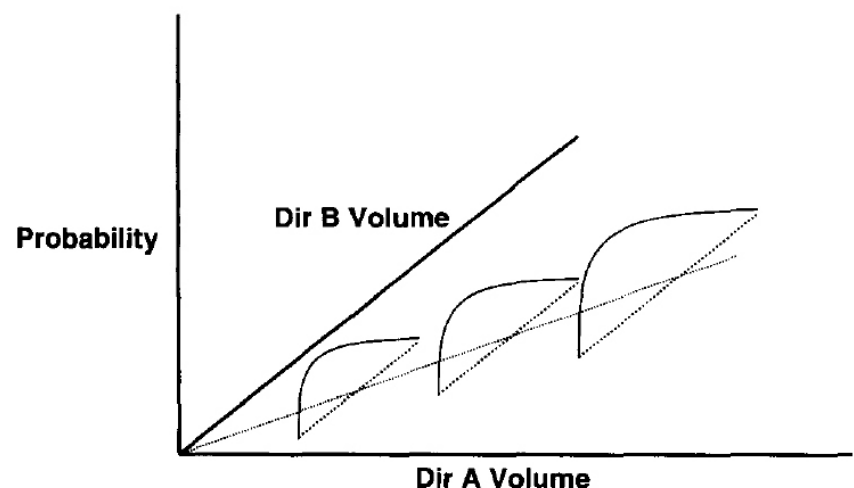

(b)

FIGURE 3 State probability distributions: $[a]$ major and $(b]$ minor. thresholds that provides the best separation of prevailing traffic conditions. State variables typically include traffic counts and occupancy data measured by detectors placed on the approaches to the signalized intersections within the network. Abbas et al. (9) described the use of discriminant analysis to obtain TRPS thresholds. However, standard discriminant analysis can only be used to obtain thresholds for one PS parameter out of the three used in TRPS (cycle, offset, and split indexes).

Knowing the plan selection parameters and corresponding optimum timing plans for a wide range of traffic conditions (i.e., from data collected over a large number of 5-minute intervals) provides a training set that can be used to derive timing plan selection rules. The rules applicable to available system controllers have the following structure:

$P=P_{k} \quad$ if $\left(x 1_{L k} \leq x 1<x 1_{U k}\right) \cap\left(x 2_{L k} \leq x 2<x 2_{U k}\right)$

$$
\cap\left(x 3_{l k} \leq x 3<x 3_{v k}\right) \quad k=1, \ldots, K
$$

where

$P=$ selected timing plan,

$P_{k}=k$ th available timing plan in controller,

$K=$ maximum number of timing plans that can be implemented in TRPS mode,

$x 1, x 2, x 3=$ three-plan selection parameters (cycle, split, and offset indexes), and

$L, U=$ lower and upper boundaries of plan selection parameters for which optimum timing plan is $P_{k}$.

The maximum number of timing plans $K$ is controller specific. For controller manufacturers approved by TxDOT, it is limited to 48 (4 cycles times 3 offsets times 4 splits).

The plan selection rules can be derived by determining the $x 1_{L k^{\prime}} x 2_{L k^{\prime}} x 3_{L k}$ lower thresholds and $x 1_{U k^{\prime}}, x 2_{U k^{\prime}} x 3_{U k}$ upper thresholds for all $\mathrm{k}$ (i.e., all available timing plans). Each observed traffic situation (from 5-minute detector outputs) can be represented by a point in the three-dimensional coordinate system of the three-plan selection parameters, and an optimum timing plan is assigned to each of these points. Therefore, determining the appropriate thresholds for these parameters is a three-dimensional classification problem. The task is to find the best separation of ob- 


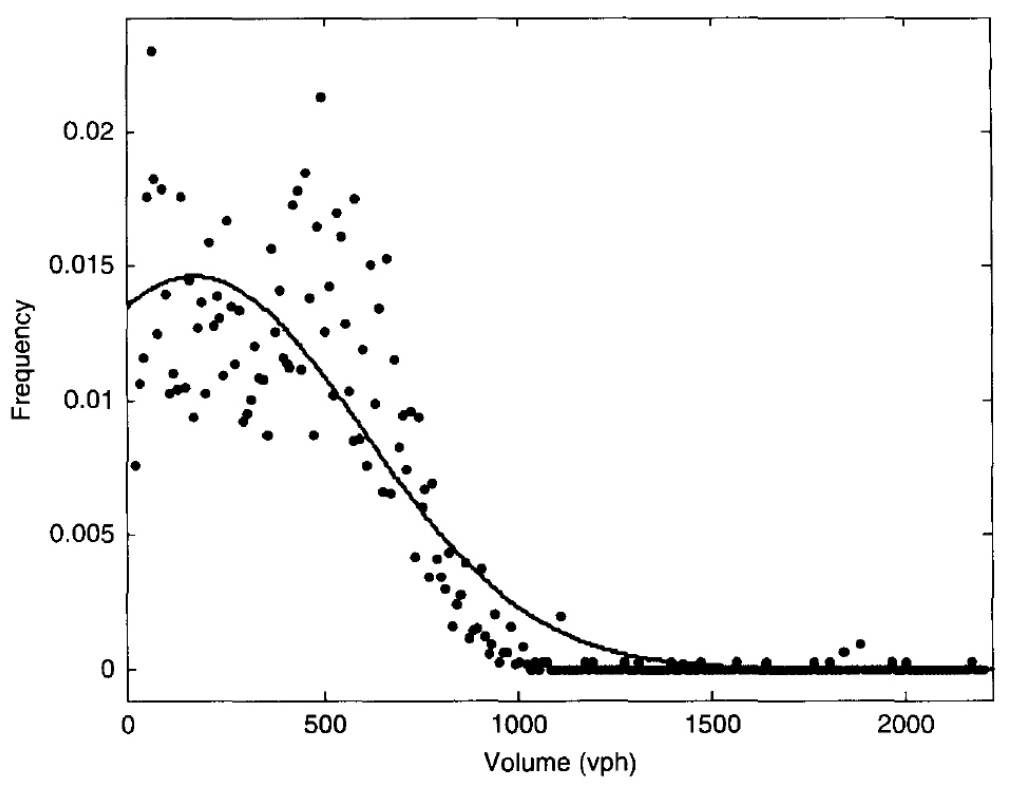

FIGURE 4 Fitted probability distribution.

served data points into $\mathrm{K}$ groups in terms of their corresponding optimum timing plan. The best separation is the one that minimizes the within-group differences and maximizes the between-group differences. Groups (i.e., observed data points from the same state) generally have nonlinear boundaries, and several groups may even overlap. Therefore, in most cases, nonlinear decision (separation) boundaries could achieve the best classification.

Several techniques, such as principal components, discriminant functions, artificial neural networks, decision-tree classifiers, and various forms of nearest-neighbor classification methods, can be used for data classification. However, the current classification problem has certain constraints that make most available techniques impractical and difficult to use. These constraints stem from the controllers' operational logic in the TRPS mode. In the TRPS mode, signal timing plans are selected from a lookup table based on real-time values of the three plan selection parameters. The lookup table consists of $K=48$ cells in a three-dimensional 4 by 4 by 3 grid. Although the 48 cells can be divided among the three-plan selection parameters in many different ways, the 4 by 4 by 3 arrangement, illustrated in Figure 5, is consistent with most

TABLE 3 Stenderd Deviations for Minor-Axis Volumes in Vehicles per Hour

\begin{tabular}{lc|rc|cc}
\hline Volume & $\begin{array}{c}\text { Standard } \\
\text { Deviation }\end{array}$ & Volume & $\begin{array}{l}\text { Standard } \\
\text { Deviation }\end{array}$ & Volume & $\begin{array}{c}\text { Standard } \\
\text { Deviation }\end{array}$ \\
\hline 100 & 55.99 & 900 & 503.91 & 1700 & 951.83 \\
200 & 111.98 & 1000 & 559.90 & 1800 & 1007.82 \\
300 & 167.97 & 1100 & 615.89 & 1900 & 1063.81 \\
400 & 223.96 & 1200 & 671.88 & 2000 & 1119.8 \\
500 & 279.95 & 1300 & 727.87 & 2100 & 1175.79 \\
600 & 335.94 & 1400 & 783.86 & 2200 & 1231.78 \\
700 & 391.93 & 1500 & 839.85 & 2300 & 1287.77 \\
800 & 447.92 & 1600 & 895.84 & & \\
\hline
\end{tabular}

controllers approved by TxDOT, and therefore it was the cell arrangement used in this project.

According to this operational logic, the decision boundaries separating different groups (i.e., traffic conditions with a common optimum timing plan) can be either parallel or orthogonal to each other. Each decision boundary is a plane parallel to one of the $x_{1}-x_{2}, x_{1}-x_{3}$, or $x_{2}-x_{3}$ planes in the $x_{1}$ $x_{2}-x_{3}$ coordinate system. The supervised discriminant algorithm developed in this study performed the plan classification and error reporting by using the following steps:

1. Calculate the Cartesian group means of all traffic states (groups);

2. Calculate initial thresholds based on the group means by placing thresholds between means of greater distances first and use this information to assign each state to one of the Cartesian cells;

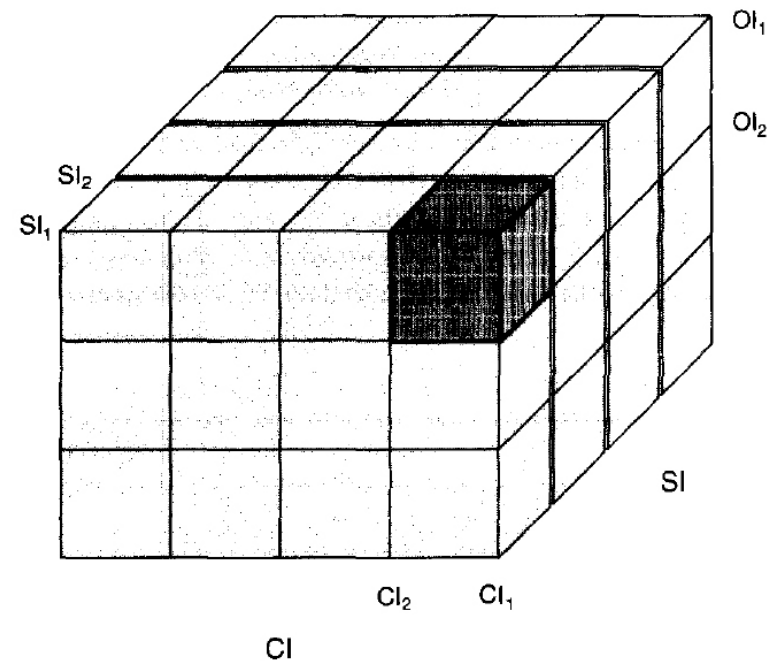

FIGURE 5 Structure for supervised linear discriminant analysis (SI, $\mathrm{Cl}$, and $\mathrm{OI}=$ split, cycle, and offset indexes, respectively]. 
3. With the GA, determine the assignment of each cell to one of the timing plans;

4. By using Steps 2 and 3, assign each state $i$ to one timing plan $T_{i}$

5. Use linear discriminant analysis for each index axis to calculate the final thresholds of that axis; and

6. On the basis of the final thresholds and cell assignments, determine the timing plan $P$, associated with the most observations from each state $i$.

\section{DESIGN GUIDELINES}

The main challenge in the TRPS configuration is the multiobjective optimization. A limited number of timing plans can be assigned to several traffic states. The assignment should be done to minimize delay (and stops) as well as the classification error. The first objective function used in the analysis is

minimize $Z_{1}=\sum_{\forall i} d\left(S_{i}, T_{i}\right)$

where $d\left(S_{i}, T_{i}\right)$ is the delay associated with operating state $S_{i}$ with plan $T_{i}$, the timing plan associated with each observation based on the association of the state to a cell and the cell to a timing plan.
The second objective function is

$C_{i} \begin{cases}1 & \text { if } T_{i} \neq P_{i} \\ 0 & \text { otherwise }\end{cases}$

where

$\operatorname{minimize} Z_{2}=\sum_{\forall i} C_{i}$

$P_{i}$ is the timing plan associated with each observation based on the majority rule.

To perform the multi objective optimization, the GA optimizer was integrated with the supervised discriminant analysis algorithm. Input data were obtained from CORSIM (10) simulation in which each of the 14 selected timing plans was run with all 1,479 traffic states. The algorithm is shown in Figure 6.

\section{Optimization Results}

The multiobjective GA was run, and a final selection of TRPS parameters was made. Of the 14 timing plans input to the program, only nine plans were used and associated to different states to provide better classification. Table 4 shows the final nine timing plans selected.

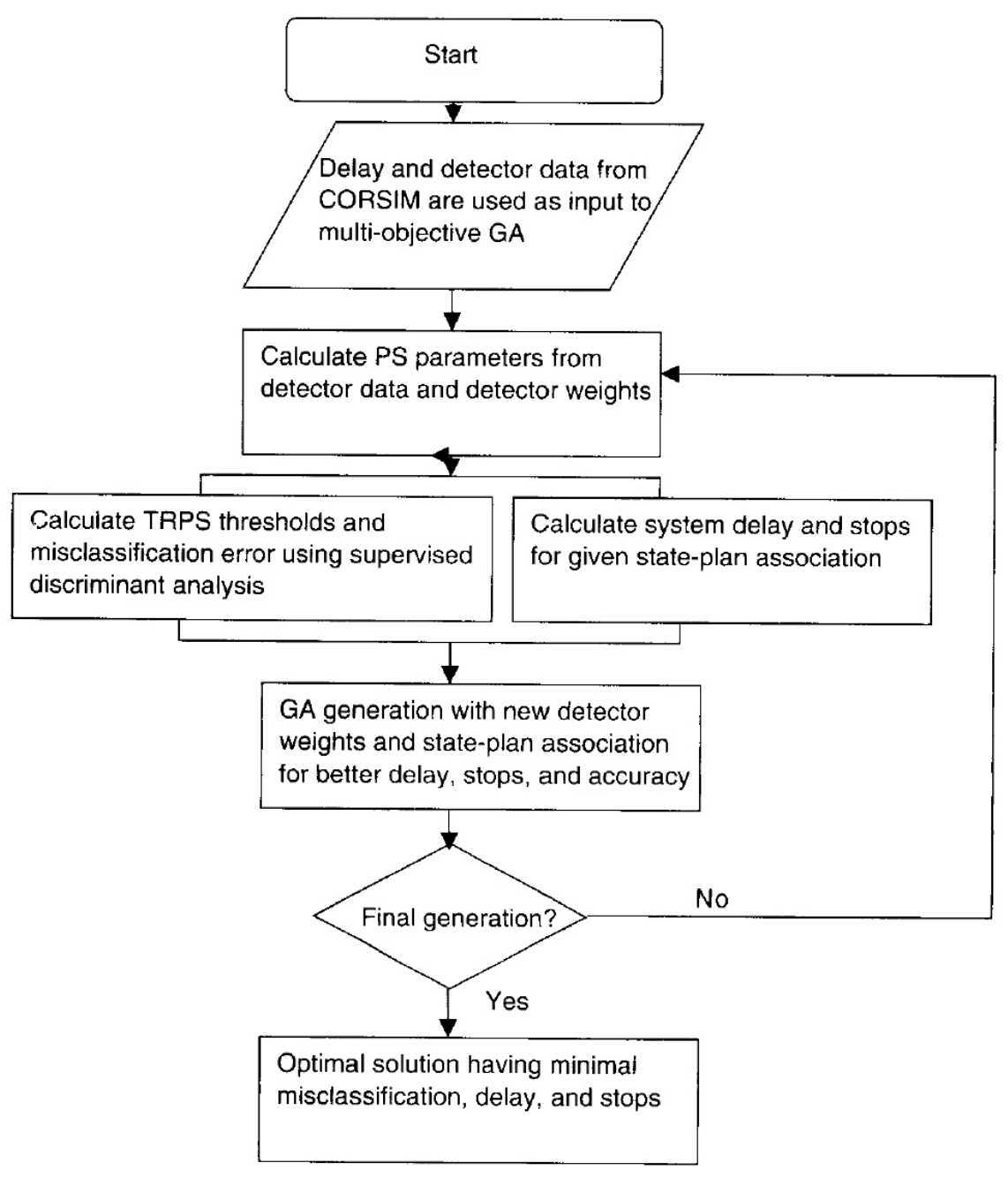

FIGURE 6 Multiobjective TRPS configuration algorithm. 
TABLE 4 Final Selection of Timing Plans

\begin{tabular}{|c|c|c|c|c|c|c|c|c|c|c|c|c|}
\hline \multirow{2}{*}{$\begin{array}{l}\text { Timing } \\
\text { Plan }\end{array}$} & \multirow[b]{2}{*}{ Intersection } & \multirow[b]{2}{*}{ Cycle } & \multicolumn{8}{|c|}{ Phase } & \multirow[b]{2}{*}{ Sequence } & \multirow[b]{2}{*}{ Offset } \\
\hline & & & 1 & 2 & 3 & 4 & 5 & 6 & 7 & 8 & & \\
\hline 1 & $\begin{array}{l}1 \\
2 \\
3 \\
4\end{array}$ & $\begin{array}{l}60 \\
60 \\
60 \\
60\end{array}$ & $\begin{array}{l}10 \\
10 \\
10 \\
10\end{array}$ & $\begin{array}{l}28 \\
30 \\
30 \\
26\end{array}$ & $\begin{array}{l}10 \\
10 \\
10 \\
11\end{array}$ & $\begin{array}{l}12 \\
10 \\
10 \\
13\end{array}$ & $\begin{array}{l}10 \\
10 \\
10 \\
13\end{array}$ & $\begin{array}{l}28 \\
30 \\
30 \\
23\end{array}$ & $\begin{array}{l}12 \\
10 \\
10 \\
11\end{array}$ & $\begin{array}{l}10 \\
10 \\
10 \\
13\end{array}$ & $\begin{array}{l}\text { Lead-lead } \\
\text { Lag-lead } \\
\text { Lead-lag } \\
\text { Lag-lead }\end{array}$ & $\begin{array}{r}0 \\
25 \\
37 \\
59\end{array}$ \\
\hline 2 & $\begin{array}{l}1 \\
2 \\
3 \\
4\end{array}$ & $\begin{array}{l}60 \\
60 \\
60 \\
60\end{array}$ & $\begin{array}{l}10 \\
10 \\
10 \\
10\end{array}$ & $\begin{array}{l}24 \\
30 \\
30 \\
26\end{array}$ & $\begin{array}{l}12 \\
10 \\
10 \\
10\end{array}$ & $\begin{array}{l}14 \\
10 \\
10 \\
14\end{array}$ & $\begin{array}{l}10 \\
10 \\
10 \\
10\end{array}$ & $\begin{array}{l}24 \\
30 \\
30 \\
26\end{array}$ & $\begin{array}{l}12 \\
10 \\
10 \\
11\end{array}$ & $\begin{array}{l}14 \\
10 \\
10 \\
13\end{array}$ & $\begin{array}{l}\text { Lead-lead } \\
\text { Lag-lead } \\
\text { Lead-lag } \\
\text { Lead-lead }\end{array}$ & $\begin{array}{r}0 \\
25 \\
33 \\
59\end{array}$ \\
\hline 3 & $\begin{array}{l}1 \\
2 \\
3 \\
4\end{array}$ & $\begin{array}{l}75 \\
75 \\
75 \\
75\end{array}$ & $\begin{array}{l}11 \\
10 \\
10 \\
10\end{array}$ & $\begin{array}{l}39 \\
45 \\
45 \\
36\end{array}$ & $\begin{array}{l}12 \\
10 \\
10 \\
14\end{array}$ & $\begin{array}{l}13 \\
10 \\
10 \\
15\end{array}$ & $\begin{array}{l}10 \\
10 \\
10 \\
11\end{array}$ & $\begin{array}{l}40 \\
45 \\
45 \\
35\end{array}$ & $\begin{array}{l}15 \\
10 \\
10 \\
13\end{array}$ & $\begin{array}{l}10 \\
10 \\
10 \\
16\end{array}$ & $\begin{array}{l}\text { Lead-lead } \\
\text { Lead-lead } \\
\text { Lead-lag } \\
\text { Lag-lead }\end{array}$ & $\begin{array}{r}0 \\
37 \\
43 \\
71\end{array}$ \\
\hline 4 & $\begin{array}{l}1 \\
2 \\
3 \\
4\end{array}$ & $\begin{array}{l}60 \\
60 \\
60 \\
60\end{array}$ & $\begin{array}{l}10 \\
10 \\
10 \\
10\end{array}$ & $\begin{array}{l}30 \\
30 \\
30 \\
29\end{array}$ & $\begin{array}{l}10 \\
10 \\
10 \\
11\end{array}$ & $\begin{array}{l}10 \\
10 \\
10 \\
10\end{array}$ & $\begin{array}{l}10 \\
10 \\
10 \\
10\end{array}$ & $\begin{array}{l}30 \\
30 \\
30 \\
29\end{array}$ & $\begin{array}{l}10 \\
10 \\
10 \\
10\end{array}$ & $\begin{array}{l}10 \\
10 \\
10 \\
11\end{array}$ & $\begin{array}{l}\text { Lead-lead } \\
\text { Lag-lead } \\
\text { Lead-lag } \\
\text { Lag-lead }\end{array}$ & $\begin{array}{r}0 \\
25 \\
35 \\
57\end{array}$ \\
\hline 5 & $\begin{array}{l}1 \\
2 \\
3 \\
4\end{array}$ & $\begin{array}{l}75 \\
75 \\
75 \\
75\end{array}$ & $\begin{array}{l}11 \\
10 \\
10 \\
10\end{array}$ & $\begin{array}{l}37 \\
45 \\
45 \\
40\end{array}$ & $\begin{array}{l}12 \\
10 \\
10 \\
10\end{array}$ & $\begin{array}{l}15 \\
10 \\
10 \\
15\end{array}$ & $\begin{array}{l}10 \\
10 \\
10 \\
10\end{array}$ & $\begin{array}{l}38 \\
45 \\
45 \\
40\end{array}$ & $\begin{array}{l}13 \\
10 \\
10 \\
12\end{array}$ & $\begin{array}{l}14 \\
10 \\
10 \\
13\end{array}$ & $\begin{array}{l}\text { Lead-lead } \\
\text { Lag-lead } \\
\text { Lead-lag } \\
\text { Lag-lead }\end{array}$ & $\begin{array}{r}0 \\
25 \\
41 \\
70\end{array}$ \\
\hline 6 & $\begin{array}{l}1 \\
2 \\
3 \\
4\end{array}$ & $\begin{array}{l}90 \\
90 \\
90 \\
90\end{array}$ & $\begin{array}{l}12 \\
10 \\
10 \\
10\end{array}$ & $\begin{array}{l}54 \\
60 \\
60 \\
53\end{array}$ & $\begin{array}{l}11 \\
10 \\
10 \\
17\end{array}$ & $\begin{array}{l}13 \\
10 \\
10 \\
10\end{array}$ & $\begin{array}{l}10 \\
10 \\
10 \\
12\end{array}$ & $\begin{array}{l}56 \\
60 \\
60 \\
51\end{array}$ & $\begin{array}{l}14 \\
10 \\
10 \\
12\end{array}$ & $\begin{array}{l}10 \\
10 \\
10 \\
15\end{array}$ & $\begin{array}{l}\text { Lead-lead } \\
\text { Lead-lag } \\
\text { Lag-lead } \\
\text { Lead-lead }\end{array}$ & $\begin{array}{r}0 \\
2 \\
33 \\
46\end{array}$ \\
\hline 7 & $\begin{array}{l}1 \\
2 \\
3 \\
4\end{array}$ & $\begin{array}{l}90 \\
90 \\
90 \\
90\end{array}$ & $\begin{array}{l}18 \\
14 \\
10 \\
10\end{array}$ & $\begin{array}{l}32 \\
46 \\
50 \\
41\end{array}$ & $\begin{array}{l}18 \\
14 \\
13 \\
10\end{array}$ & $\begin{array}{l}22 \\
16 \\
17 \\
29\end{array}$ & $\begin{array}{l}10 \\
12 \\
16 \\
23\end{array}$ & $\begin{array}{l}40 \\
48 \\
44 \\
28\end{array}$ & $\begin{array}{l}10 \\
13 \\
14 \\
18\end{array}$ & $\begin{array}{l}30 \\
17 \\
16 \\
21\end{array}$ & $\begin{array}{l}\text { Lead-lead } \\
\text { Lag-lead } \\
\text { Lag-lead } \\
\text { Lead-lag }\end{array}$ & $\begin{array}{r}0 \\
25 \\
25 \\
43\end{array}$ \\
\hline 8 & $\begin{array}{l}1 \\
2 \\
3 \\
4\end{array}$ & $\begin{array}{l}75 \\
75 \\
75 \\
75\end{array}$ & $\begin{array}{l}15 \\
11 \\
10 \\
10\end{array}$ & $\begin{array}{l}27 \\
39 \\
40 \\
33\end{array}$ & $\begin{array}{l}15 \\
11 \\
11 \\
10\end{array}$ & $\begin{array}{l}18 \\
14 \\
14 \\
22\end{array}$ & $\begin{array}{l}10 \\
10 \\
13 \\
20\end{array}$ & $\begin{array}{l}32 \\
40 \\
37 \\
23\end{array}$ & $\begin{array}{l}15 \\
11 \\
11 \\
15\end{array}$ & $\begin{array}{l}18 \\
14 \\
14 \\
17\end{array}$ & $\begin{array}{l}\text { Lead-lead } \\
\text { Lead-lead } \\
\text { Lead-lag } \\
\text { Lag-lead }\end{array}$ & $\begin{array}{r}0 \\
26 \\
29 \\
60\end{array}$ \\
\hline 9 & $\begin{array}{l}1 \\
2 \\
3 \\
4\end{array}$ & $\begin{array}{l}75 \\
75 \\
75 \\
75\end{array}$ & $\begin{array}{l}15 \\
11 \\
10 \\
10\end{array}$ & $\begin{array}{l}26 \\
40 \\
40 \\
33\end{array}$ & $\begin{array}{l}16 \\
11 \\
11 \\
17\end{array}$ & $\begin{array}{l}18 \\
13 \\
14 \\
15\end{array}$ & $\begin{array}{l}10 \\
10 \\
13 \\
20\end{array}$ & $\begin{array}{l}31 \\
41 \\
37 \\
23\end{array}$ & $\begin{array}{l}18 \\
11 \\
11 \\
15\end{array}$ & $\begin{array}{l}16 \\
13 \\
14 \\
17\end{array}$ & $\begin{array}{l}\text { Lead-lead } \\
\text { Lead-lead } \\
\text { Lead-lag } \\
\text { Lag-lead }\end{array}$ & $\begin{array}{r}0 \\
26 \\
28 \\
60\end{array}$ \\
\hline
\end{tabular}

TRPS Weights, Thresholds, and Table Lookup Entries

The detector weights obtained are shown in Table 5, and the plan lookup table entries are given in Table 6. The TRPS thresholds are as follows:

$\begin{array}{llll}\text { Level } & \text { Cycle } & \text { Offset } & \text { Split } \\ 1 & 10 & 59 & 34 \\ 2 & 12 & 65 & 41 \\ 3 & 19 & 68 & -\end{array}$

A stepwise discriminant analysis was used to deter- mine the critical location of the system detector (8). It was found that a collection of 13 system detectors placed at strategic locations can provide a robust and accurate classification of different traffic states. Recommended locations of system detectors are shown in Figure 7.

System detectors are located 400 feet upstream of the traffic signal, in the inside lane, except for Detectors 3, 6, 10 , and 12, which are located 300 feet upstream of the leftturn approach. Thoughtful investigation of the system detector locations in Figure 7 suggests that the TRPS mechanism works best when the following traffic movements can be sensed:

TABLE 5 Detector Weights

\begin{tabular}{|c|c|c|c|c|c|c|c|c|c|c|c|c|c|c|}
\hline \multirow[b]{2}{*}{ Direction } & \multirow[b]{2}{*}{ Actuation } & \multicolumn{13}{|c|}{ Detector } \\
\hline & & 1 & 2 & 3 & 4 & 5 & 6 & 7 & 8 & 9 & 10 & 11 & 12 & 13 \\
\hline \multirow[t]{2}{*}{ Inbound } & Count & 13 & 83 & 27 & 14 & 92 & 76 & 1 & 12 & 59 & 77 & 92 & 65 & 85 \\
\hline & Occupancy & 12 & 21 & 75 & 9 & 10 & 52 & 16 & 52 & 21 & 25 & 5 & 26 & 13 \\
\hline \multirow[t]{2}{*}{ Outbound } & Count & 98 & 52 & 22 & 63 & 91 & 5 & 1 & 99 & 44 & 4 & 6 & 61 & 1 \\
\hline & Occupancy & 86 & 68 & 45 & 10 & 63 & 38 & 34 & 38 & 60 & 13 & 5 & 43 & 27 \\
\hline \multirow[t]{2}{*}{ Cross } & Count & 3 & 53 & 15 & 79 & 33 & 1 & 74 & 10 & 90 & 10 & 95 & 79 & 91 \\
\hline & Occupancy & 52 & 12 & 34 & 72 & 29 & 22 & 14 & 22 & 11 & 56 & 12 & 15 & 25 \\
\hline
\end{tabular}


TABLE 6 TAPS Plan Lookup Table Entries

\begin{tabular}{lcccc}
\hline & & \multicolumn{3}{l}{ Split } \\
\cline { 3 - 5 } Cycle & Offset & 1 & 2 & 3 \\
\hline 1 & 1 & 4 & 4 & 6 \\
1 & 2 & 4 & 4 & 6 \\
1 & 3 & 7 & 7 & 7 \\
1 & 4 & 3 & 9 & 6 \\
2 & 1 & 5 & 7 & 1 \\
2 & 2 & 7 & 7 & 4 \\
2 & 3 & 9 & 4 & 4 \\
2 & 4 & 9 & 7 & 5 \\
3 & 1 & 4 & 9 & 2 \\
3 & 2 & 8 & 8 & 7 \\
3 & 3 & 8 & 8 & 2 \\
3 & 4 & 4 & 1 & 7 \\
4 & 1 & 7 & 2 & 2 \\
4 & 2 & 4 & 2 & 2 \\
4 & 3 & 3 & 3 & 4 \\
4 & 4 & 3 & 5 & 4 \\
\hline & & & &
\end{tabular}

1. Through movements at the exterior intersections (Detectors 1, 2, 4 and 5, and 9, 10, 11 and 13),

2. Left-turning movements that leave or exit the coordinated system (Detectors 3 and 6 and 10 and 12), and

3. Movement at one of the cross streets (the cross street with the most traffic variation).

It should also be noted that Detectors 2 and 10 assist the TRPS mechanism in estimating how much traffic goes through the system and how much traffic disappears (or appears) locally.

\section{HITL Simulation}

In order to test the guidelines developed in this study, it was necessary to simulate a case in which a surge of traffic occurs within a normal traffic period. CORSIM simulation was used with HITL to test the performance of TRPS. HITL simulation of traffic was necessary in this case because there is a need to replicate exactly what a controller would do. In HITL simulation, the controller receives the detector information from the simulator and behaves exactly as it would in the field. The control decisions (signal indications, plan changes, etc.) are then sent back to the computer simulation.

\section{Simulation Results}

Three different traffic states of $30 \mathrm{~min}$ each were simulated (Table 7). Inserting a surge of high-volume traffic into low-volume traffic simulates an event or incident in which TRPS would be useful. Also, this state could be looked at as a difference in traffic patterns due to some developmental changes or commercial activities, or both, in which some high traffic activity occurs in the middle of the day.

Figure 8 shows the three PS parameters calculated from system detector occupancy and count data during the simulation period. Also shown are the thresholds to switch between a PS index and the next level. It should be noted how PS parameters change values during the simulation as the traffic state changes from one level to the next. Figure 9 shows the index and the plan assigned to the lookup table entry. TRPS was found to bring up the most appropriate timing plan in a stable and timely fashion.

\section{CONCLUSION AND RECOMMENDATIONS}

The TRPS mode provides a mechanism by which the traffic signal system is able to change timing plans in real time in response to changes in traffic conditions. However, there are limited guidelines to configure a TRPS system for optimal and robust operation.

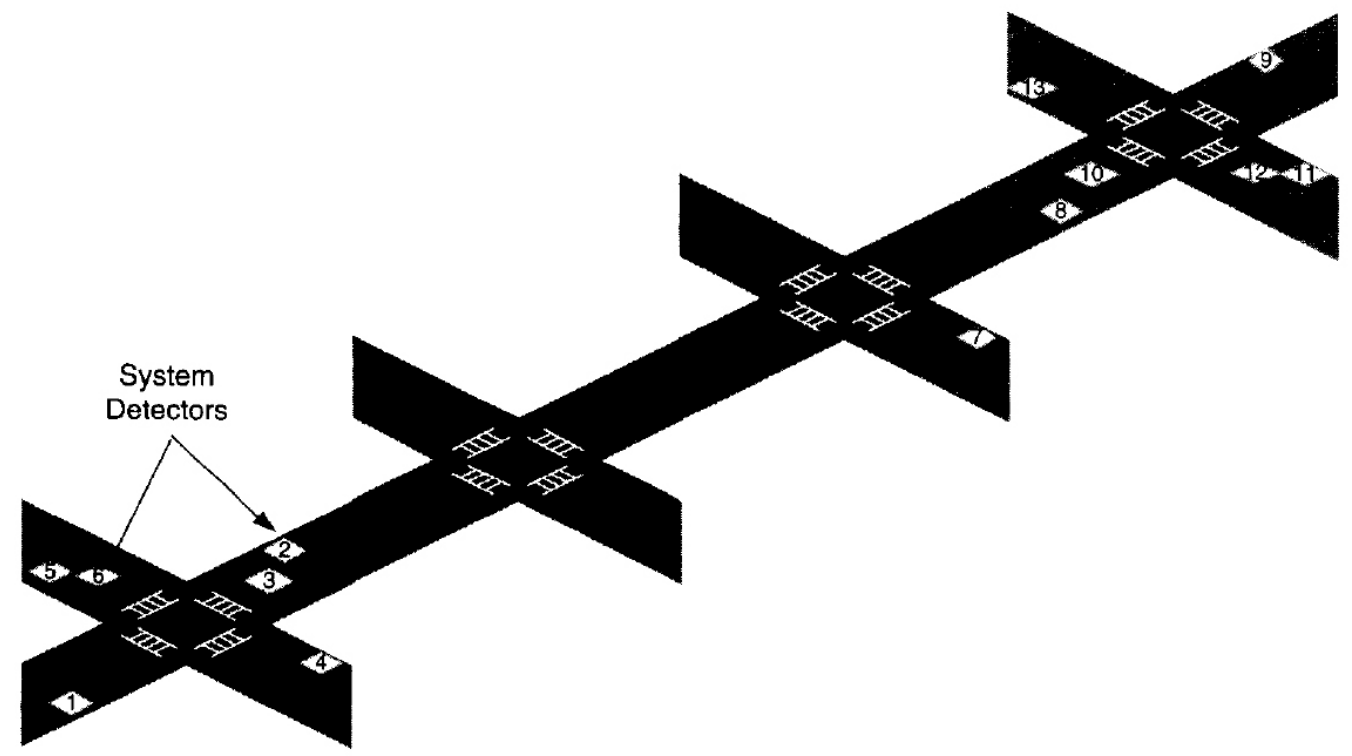

FIGURE 7 System detector locations. 
TABLE 7 Traffic States Used in HITL Simulation

\begin{tabular}{lccccccc}
\hline State & EB-Through & SB-Left & NB-Right & WB-Through & NB-Left & SB-Right & Cross-Street \\
\hline 1 & 1200 & 0 & 0 & 400 & 0 & 0 & 150 \\
2 & 1600 & 200 & 0 & 400 & 0 & 200 & 150 \\
3 & 1200 & 300 & 200 & 1200 & 300 & 200 & 150 \\
\hline
\end{tabular}

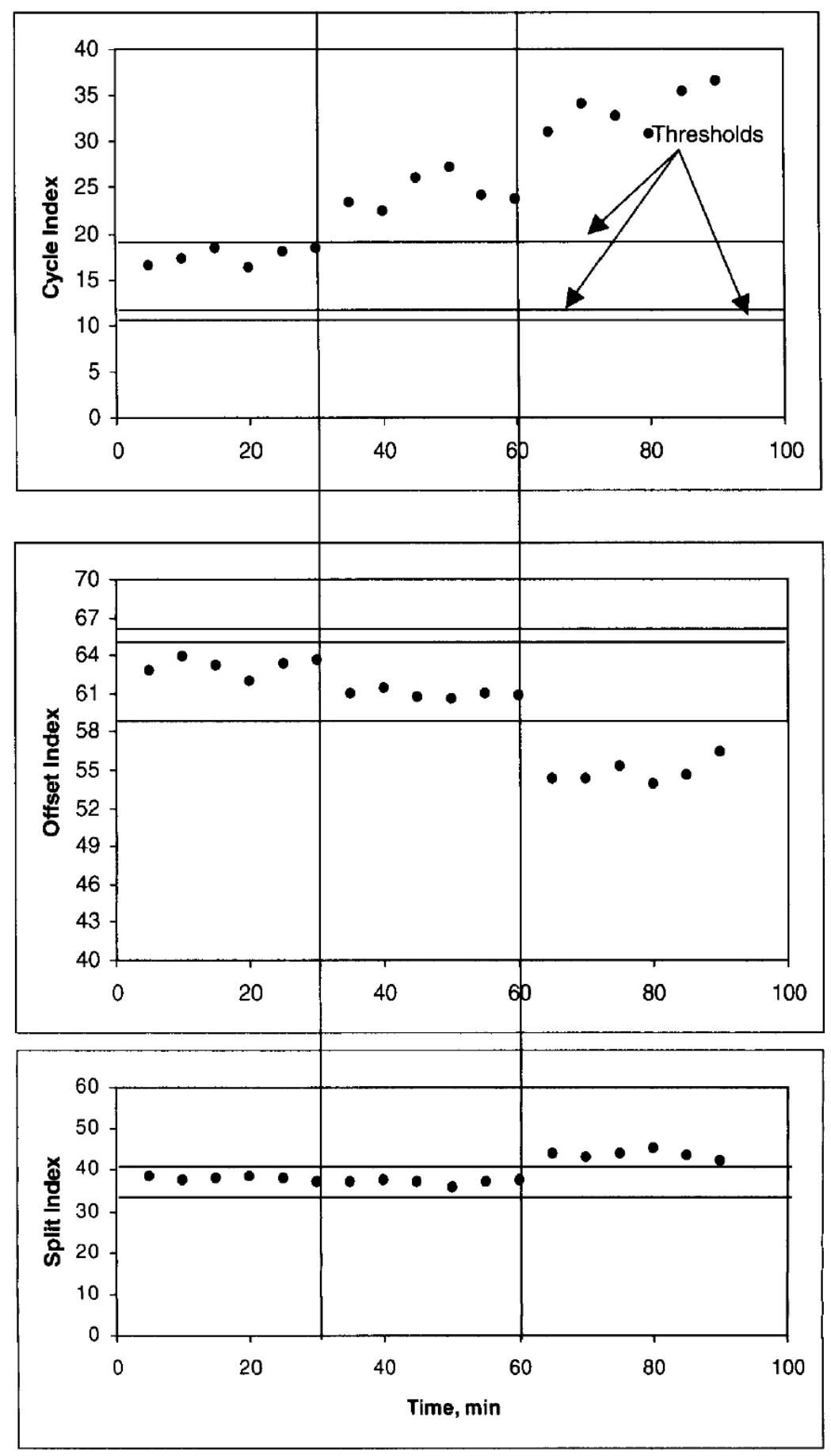

FIGURE 8 PS parameter change during HITL simulation. 


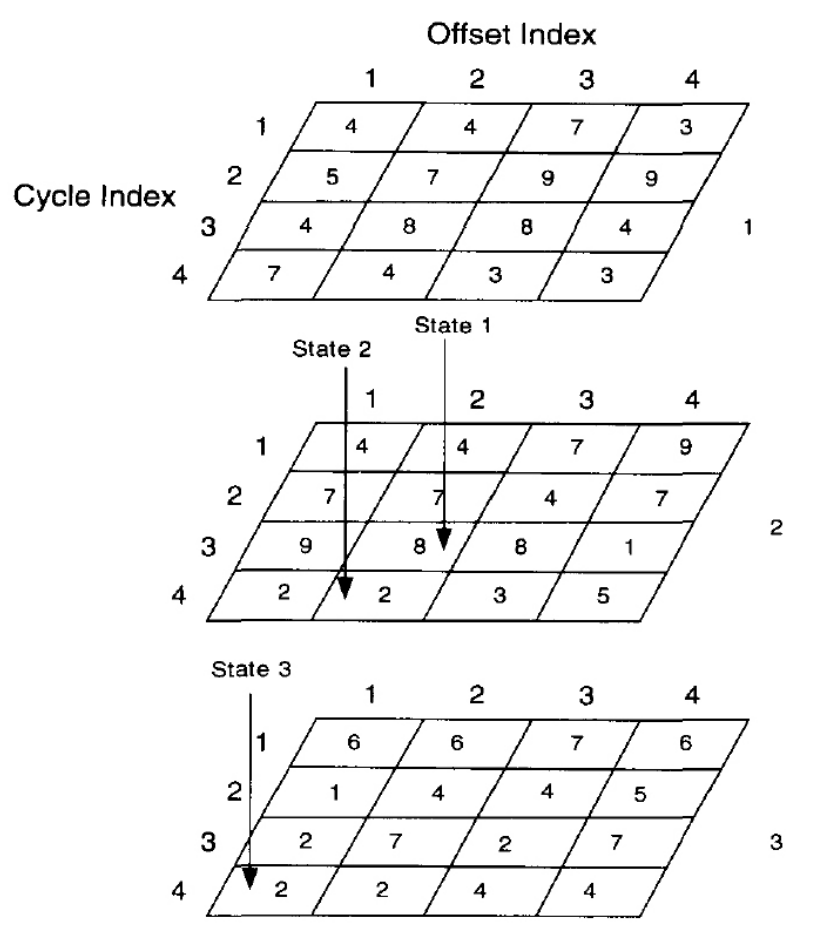

FIGURE 9 Timing plan assignment in lookup table.

In this paper, a new TRPS configuration methodology was presented. The methodology followed a comprehensive approach that utilized a multiobjective evolutionary algorithm and a supervised discriminant analysis. The multi objective algorithm resulted in a selection of nine timing plans to be used with the TRPS mode. The combination of these plans is expected to achieve at least $53 \%$ savings in delay and $16 \%$ savings in stops compared with an aging TOD design. The study showcased an effective implementation of the TRPS mode by using HITL simulation. Engineers can implement the detector weights, timing plans, and lookup tables presented in this paper as an initial design. The thresholds presented can be fine-tuned to better suit the traffic distributions in individual systems. Ultimately, the authors recommend the development of computer software to automate the procedure so that more customized designs can be produced.

\section{ACKNOWLEDGMENTS}

This work was sponsored by TxDOT and was conducted for TxDOT's Research and Technology Implementation Office. The materials and methods presented were developed as part of TxDOT Project 0-4421, A Simplified Approach for Selecting Optimal Traffic Responsive Control Parameters. The authors recognize the project director, Henry Wickes, for his support and guidance throughout the duration of this project.

\section{REFERENCES}

L 1. Hanbali, R. M. and C. J. Fornal. Methodology for EvaluatI ing Effectiveness of Traffic-Responsive Systems on Intersection

T Congestion and Traffic Safety. Transportation Research Record 1603, 1997, pp. 137-149.

2. Nelson, E., M. Abbas, G. Shoup and D. Bullock. Development N of Closed Loop System Evaluation Procedures. Report FHWA/ D IN/JTRP. FHW A, U.S. Department of Transportation, 2000.

E 3. Master Controller Software. Naztec, Inc., Sugarland, Tex., × 2002 .

4. ASC/2M-1000 Zone Master Programming Manual. Econolite Control Products, Inc., Anaheim, Calif., 1996.

5. MARC 300 Series Master Controller. Automatic Signal/Eagle Signal, Austin, Tex., 1997.

6. National Transportation Communications for ITS Protocol: Field Management Stations Draft. NTCIP 1210. National Electrical Manufacturers Association, Rosslyn, Va., 2004.

7. Balke, K. N., R. S. Keithireddipalli and C. L. Brehmer. Guidelines for Implementing Traffic Responsive Mode in TxDOT Closed-Loop Traffic Signal Systems. Research Report 2929-3F, Project 7-2929. Texas Transportation Institute, Texas A\&M University System, College Station, 1997.

8. Chaudhary, N., V. Kovvali, C. Chu and S. Alam. Software for Timing Signalized Arterials. Research Report 4020-1. Texas Transportation Institute, Texas A\&M University System, College Station, 2002. 9. Abbas, M. M., N. A. Chaudhary, A. Sharma, S. P. Venglar and R. J. Engelbrecht. Methodology for Determination of Optimal Traffic Responsive Plan Selection Control Parameters. Research Report 4421-1. Texas Transportation Institute, Texas A\&M University System, College Station, 2003.

10. ITT Systems \& Sciences Corporation. CORSIM User's Manual. FHWA, U.S. Department of Transportation, 2003.

The Traffic Signal Systems Committee sponsored publication of this paper. 